\title{
Le Roman du signe - Fiction et herméneutique au XIX siècle, sous la direction de Andrea Del Lungo et Boris Lyon-Caen
}

\section{Fabiola Baldo}

\section{(2) OpenEdition}

\section{$\checkmark$ Journals}

\section{Edizione digitale}

URL: http://journals.openedition.org/studifrancesi/9021

DOI: ERREUR PDO dans/localdata/www-bin/Core/Core/Db/Db.class.php L.34 : SQLSTATE[HY000]

[2006] MySQL server has gone away

ISSN: 2421-5856

\section{Editore}

Rosenberg \& Sellier

\section{Edizione cartacea}

Data di pubblicazione: 1 octobre 2008

Paginazione: 487

ISSN: 0039-2944

\section{Notizia bibliografica digitale}

Fabiola Baldo, «Le Roman du signe - Fiction et herméneutique au xix ${ }^{\mathrm{e}}$ siècle, sous la direction de Andrea Del Lungo et Boris Lyon-Caen», Studi Francesi [Online], 155 (LII | II) | 2008, online dal 30 novembre 2015, consultato il 08 janvier 2021. URL: http://journals.openedition.org/studifrancesi/9021 ; DOI: https://doi.org/ERREUR PDO dans /localdata/www-bin/Core/Core/Db/Db.class.php L.34: SQLSTATE[HY000] [2006] MySQL server has gone away

Questo documento è stato generato automaticamente il 8 janvier 2021.

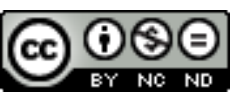

Studi Francesi è distribuita con Licenza Creative Commons Attribuzione - Non commerciale - Non opere derivate 4.0 Internazionale. 


\title{
Le Roman du signe - Fiction et herméneutique au XIX ${ }^{\mathrm{e}}$ siècle, sous la direction de Andrea Del Lungo et Boris Lyon-Caen
}

\author{
Fabiola Baldo
}

\section{NOTIZIA}

Le Roman du signe - Fiction et herméneutique au XIX siècle, sous la direction de Andrea DEL LUNGO et Boris LYON-CAEN, «Essais et Savoirs» PUV, Saint-Denis, 2007, pp. 283.

1 Gli studi riuniti in questo volume percorrono le molteplici forme assunte dal concetto di segno, che articolano la complessità della trama del romanzo del XIX secolo, giustificandone la straordinaria produzione. Traccia, impronta, marchio, espressione di caratteristiche che riassumono le convenzioni, il segno, per sua natura, rinvia alla scrittura e dunque ai generi, alla struttura e alla lingua del romanzo, in quanto elemento essenziale per costruire significato.

Da una parte il segno si esplicita come dettaglio puro, legato fisicamente al suo oggetto: nelle lacrime del romanzo sentimentale (Le Lys dans la vallée di Balzac, Dominique di Fromentin, L'Éducation sentimentale di Flaubert) e nelle acconciature delle nobildonne, sigillo di distinzione e di appartenenza sociale. Dall'altra, in Balzac (Jérôme DAVID, Le sens pratique du détail) ad esempio, è indizio di ciò che si verifica nel testo e che può essere decodificato solo da un lettore perspicace, divenendo una sorta di categoria critica caratterizzata da fluttuazione semantica. Nel romanzo storico il dettaglio è prova di erudizione della scrittura e risponde al tentativo di legittimare un genere che aspira a collocarsi accanto alla poesia e al teatro. In Madame Bovary di Flaubert, definisce la norma borghese attraverso la forma della mediocrità alimentare, simboleggiata dalla cuisine pot-au-feu (Julie-Manon DOUCET, Poétique du signe alimentaire 
dans Madame Bovary). Il cibo si fa sinonimo di convenzione, ma anche elemento di trasgressione. Non a caso il destino di Emma si iscrive in qualche modo nelle bevande (l'ebbrezza come condizione vitale per sfuggire alla noia dell'esistenza), accompagnando via via il decadimento della protagonista.

Nei racconti e nelle novelle di Maupassant l'oggetto liturgico, spogliato del suo significato religioso e investito di un valore profano o addirittura dissacrante, mette in forma la critica implicita portata alla religione dall'autore (Noëlle BENHAMOU, L'objet de culte détourné: la perversion du signe dans les contes et nouvelles de Maupassant). Così in Le lit, la casula, veste religiosa, è il lieu idéal per nascondere il peccato commesso dal prete che, colpevole di amare, aggrava la sua situazione indossando un abito il cui valore religioso riconosciuto coesiste con l'oggetto del suo errore. Nelle opere di Hugo, NotreDame de Paris e Les Misérables, la scrittura delinea un universo narrativo fortemente segnato dallo stigma e ciò attraverso il ricorso a un vocabolario dominato dal mostruoso e dall'esclusione (Christèle coULEAU, «Stigmates». Du signe particulier au signal narratif). Segno discriminante, lo stigma distingue per poter escludere meglio e, riprendendo Erving Goffman, definisce identità, disegna confini, articola il visibile e il nascosto, implica un giudizio mettendo in scena valori individuali e collettivi. Marchio di condanna, si manifesta anche come desiderio di redenzione, trasformando il discorso narrativo in riflessione sulla società, sulla sua capacità di reintegrare chi ha commesso la colpa, ma anche sulla sua capacità di perdono, superando in tal modo l'immagine cristiana per esprimere un'umanità vera, capace di raggiungere il suo essere perfettibile.

In Huysmans (Jérôme solal, Huysmans en rade, ou la mort du signe), Parigi è oggetto della scrittura e brulica di segni della modernità. Dopo l'isolamento della campagna, il rientro in città diventa per Jacques Marles, protagonista di En rade, un ritorno al senso, al segno, al soggettivo. Mademoiselle de Maupin di Théophile Gautier (Agate LECHEVALIER et Nicolas WANLIN, Scénario sémiotique et dialectique des signes dans "Mademoiselle de Maupin" de Théophile Gautier) disegna la realtà come luogo di ambiguità e di instabilità dei segni, al punto che solo in sogno o a teatro si ritrovano apparenze rassicuranti. Confusione di identità e conseguente turbamento del lettore caratterizzano Le Rouge et le Noir di Stendhal, in cui il tema del segno e del codice sono strettamente correlati a quelli della maschera e dell'ipocrisia, giacché il segno opera una mediazione tra ciò che viene socialmente valorizzato e di cui la passionalità di Julien è espressione, e le determinazioni sociali che conferiscono valore di paradigma al destino di Sorel (François VANOOSTHUYSE, Julien et les signes. Sur la sémiologie matérialiste de Stendhal).

5 Come si vede il concetto di segno si caratterizza per una forte specificità della sua accezione nel corso del xix secolo. Spesso è percepito come indizio concreto che costruisce poi significato all'interno di un sistema di segni, fondando la dialettica dell'enigma e della rivelazione, assurgendo a nucleo della rappresentazione realista e della funzione narrativa, quindi della struttura del romanzo. 